\title{
Pulsed Laser Deposition of High Temperature Protonic Films
}

\author{
F. W. Dynys ${ }^{*}$, M. H. Berger ${ }^{* *}$ and A. Sayir*** \\ * NASA-GRC, 21000 Brookpark Rd., Cleveland, OH 44135, USA \\ ** Ecole des Mines de Paris, BP 87, 91003 Evry Cedex, France \\ *** NASA-GRC/CWRU, 21000 Brookpark Rd., Cleveland, OH 44135, USA \\ email: Frederick.W.Dynys@,nasa.gov
}

\begin{abstract}
Pulsed laser deposition has been used to fabricate nanostructured $\mathrm{BaCe}_{0.85} \mathrm{Y}_{0.15} \mathrm{O}_{3-\delta}$ films. Protonic conduction of fabricated $\mathrm{BaCe}_{0.85} \mathrm{Y}_{0.15} \mathrm{O}_{3-\delta}$ films was compared to sintered $\mathrm{BaCe}_{0.85} \mathrm{Y}_{0.15} \mathrm{O}_{3-\delta}$. Sintered samples and laser targets were prepared by sintering $\mathrm{BaCe}_{0.85} \mathrm{Y}_{0.15} \mathrm{O}_{3-\delta}$ powders derived by solid state synthesis. Films 1 to $8 \mu \mathrm{m}$ thick were deposited by $\mathrm{KrF}$ excimer laser on porous $\mathrm{Al}_{2} \mathrm{O}_{3}$ substrates. Thin films were fabricated at deposition temperatures of 700 to $950{ }^{\circ} \mathrm{C}$ at $\mathrm{O}_{2}$ pressures up to $200 \mathrm{mTorr}$ using laser pulse energies of $0.45-0.95 \mathrm{~J}$. Fabricated films were characterized by x-ray diffraction, electron microscopy and electrical impedance spectroscopy. Single phase $\mathrm{BaCe}_{0.85} \mathrm{Y}_{0.15} \mathrm{O}_{3-\delta}$ films with a columnar growth morphology are observed with preferred crystal growth along the [100] or [001] direction. Results indicate [100] growth dependence upon laser pulse energy. Electrical conductivity of bulk samples produced by solid state sintering and thin film samples were measured over a temperature range of $100{ }^{\circ} \mathrm{C}$ to $900{ }^{\circ} \mathrm{C}$. Electrical conduction behavior was dependent upon film deposition temperature. Maximum conductivity occurs at deposition temperature of $900{ }^{\circ} \mathrm{C}$; the electrical conductivity exceeds the sintered specimen. All other deposited films exhibit a lower electrical conductivity than the sintered specimen. Activation energy for electrical conduction showed dependence upon deposition temperature, it varied
\end{abstract}


from $115 \mathrm{KJ}$ to $54 \mathrm{KJ}$. Film microstructure was attributed to difference in electrical conductivity of the $\mathrm{BaCe}_{0.85} \mathrm{Y}_{0.15} \mathrm{O}_{3-\delta}$ films.

Keywords: Thin films, pulse laser deposition, protonic, ceramic, perovskite

\section{Introduction}

Achieving high protonic conductivity with thermodynamic stability is considered to be a key problem for high temperature protonic conducting (HTPC) materials for electrochemical applications. Applications include fuel cells, gas sensors, gas purification systems and steam electrolyzers that will provide economic and ecological benefits. HTPC perovskite based ceramics was discovered by Iwahara et al. ${ }^{1}$ These materials exhibit dominant proton transport at temperatures up around $800^{\circ} \mathrm{C}$.

Hydrogen permeation rate for HTPC materials has been found to be inversely proportional to membrane thickness. ${ }^{2}$ Thus, reduction in HTPC membrane thickness is a practical approach to enhance the hydrogen permeation rate. To fabricate thin HTPC membranes on the order of $25 \mu \mathrm{m}$ or less, they have to be supported using porous structures to provide mechanical strength. Successful processing of inexpensive membranes fabricated by particle deposition methods is hindered by high sintering temperatures that exceed $1500{ }^{\circ} \mathrm{C} .^{3}$ Reaction between the substrate and HTPC membrane is a processing problem. Pulsed laser deposition (PLD) is ideally suited to investigate protonic conductivity of perovskite films because the complex target composition can be reproduced at the substrate. The ease with which the stoichiometry of a multi-component system can be maintained in the deposited films is a significant advantage for PLD over other conventional physical vapour deposition techniques. PLD is being routinely used to deposit high quality, highly oriented thin films of multi-component oxide materials such as superconductors, ferroelectrics, ferrites, and biomaterials. ${ }^{4}$ This paper reports our work on the deposition of $\mathrm{BaCe}_{0.85} \mathrm{Y}_{0.15} \mathrm{O}_{3-\delta}$ thin films by 
PLD. The goal is to enhance protonic conduction by reduction of substrate thickness and utilization of nano-crystalline structures. Enhanced grain boundary conduction has been reported for nanocrystalline $\mathrm{CeO}_{2}$ and $\mathrm{Y}_{2} \mathrm{O}_{3}$ stabilized $\mathrm{ZrO}_{2}$ films. ${ }^{5-7}$ Deposition temperatures ranging from 700 to $950{ }^{\circ} \mathrm{C}$ produced nano-crystalline films with columnar growth morphology. The influence of the processing parameters on the crystalline property and electrical conductivity are presented.

\section{Experimental}

High-density $\mathrm{BaCe}_{0.85} \mathrm{Y}_{0.15} \mathrm{O}_{3-\delta}(\mathrm{BCY})$ targets and bulk samples were fabricated from powders synthesized by solid state reaction. Targets and bulk samples were sintered at 1650 ${ }^{\circ} \mathrm{C}$. A previous paper describes the powder synthesis and sintering in more detail. ${ }^{8} \mathrm{BCY}$ films were grown in a stainless steel high vacuum chamber evacuated to a base pressure of $1 \times 10^{-6}$ Torr using a turbo molecular pump. A 248-nm KrF excimer laser was utilized to grow BCY films. Table I provides the process conditions for thin film fabrication. The target was rotated Process Conditions

\begin{tabular}{|c|c|c|c|c|c|}
\hline Sample & Temperature & Pressure & Pulse Rate & $\begin{array}{c}\text { Pulse } \\
\text { Energy }\end{array}$ & $\begin{array}{c}\text { Film } \\
\text { Thickness }\end{array}$ \\
\hline 3605 & $950{ }^{\circ} \mathrm{C}$ & $20 \mathrm{mTorr}$ & $5 \mathrm{~Hz}$ & $0.972 \mathrm{~J}$ & $3.6 \mu \mathrm{m}$ \\
\hline 2805 & $950^{\circ} \mathrm{C}$ & $20 \mathrm{mTorr}$ & $5 \mathrm{~Hz}$ & $1.037 \mathrm{~J}$ & $3.2 \mu \mathrm{m}$ \\
\hline 2705 & $900^{\circ} \mathrm{C}$ & $20 \mathrm{mTorr}$ & $5 \mathrm{~Hz}$ & $1.137 \mathrm{~J}$ & $4.8 \mu \mathrm{m}$ \\
\hline 2505 & $700^{\circ} \mathrm{C}$ & $200 \mathrm{mTorr}$ & $5 \mathrm{~Hz}$ & $0.583 \mathrm{~J}$ & $4.1 \mu \mathrm{m}$ \\
\hline 2405 & $700^{\circ} \mathrm{C}$ & $100 \mathrm{mTorr}$ & $5 \mathrm{~Hz}$ & $0.672 \mathrm{~J}$ & $1.7 \mu \mathrm{m}$ \\
\hline 0704 & $800^{\circ} \mathrm{C}$ & $30 \mathrm{mTorr}$ & $4 \mathrm{~Hz}$ & $0.540 \mathrm{~J}$ & $7.9 \mu \mathrm{m}$ \\
\hline
\end{tabular}
around its axis to ensure uniform ablation, mounted at an angle of $45^{\circ}$ to the laser beam; the target surface was parallel to the substrate surface. The laser beam was focused to a beam size of $4.2 \mathrm{~cm}^{2}$ on the BCY target. Target to substrate distance was kept at $101 \mathrm{~mm}$ to attain sufficient interaction between the plasma plume and the process gas. Substrates were attached to a resistance heater; temperature was monitored by a thermocouple attached to the inner wall of the heater block. Substrate temperature was varied from 700 to $950{ }^{\circ} \mathrm{C}$. Closed loop pressure control was used to maintain a chamber pressure of 
20 to 200 mTorr using $\mathrm{O}_{2}$ as the process gas. Film growth rate was approximately 0.05 $\mathrm{nm} /$ pulse. The as-grown films were cooled to room temperature at a rate of $5{ }^{\circ} \mathrm{C} / \mathrm{min}$ at $\mathrm{O}_{2}$ pressures listed in Table I. No failure of the BCY film was observed at this cooling rate. Porous $\mathrm{Al}_{2} \mathrm{O}_{3}$ substrates were used for thin film deposition. $\mathrm{Al}_{2} \mathrm{O}_{3}$ substrates were prepared by pressing Biakowski A-10 powder into discs and sintering the disc at $1100{ }^{\circ} \mathrm{C}$ for $1 \mathrm{hr}$. to give it sufficient handling strength. The crystalline structure of the as-deposited films was characterized by x-ray diffraction (XRD) and the microstructures examined by scanning electron microscope (SEM) and transmission electron microscope (TEM). Film thickness was determined by electron microscopy. The x-ray diffractometer was equipped with a $\mathrm{Cu} \mathrm{K}_{\alpha}$ source with a wavelength of $0.1540 \mathrm{~nm}$. The operating conditions were $45 \mathrm{KV}$ and $40 \mathrm{~mA}$. Scans were conducted at $3 \% \mathrm{~min}$ with a sampling interval of $0.02^{\circ}$.

The impedance as a function of the frequency and temperature were measured by electrical impedance spectroscopy (EIS). Solartron 1260/1296 combined with ProboStat (NorECs Norwegian Electro Ceramics AS) test fixture was used to acquire the impedance spectrum from 0.1 to $1 \mathrm{MHz}$ at temperatures up to $950{ }^{\circ} \mathrm{C}$. Platinum or silver electrodes were used for EIS measurements. The EIS measurement was controled by a computer using Labview software (National Instruments Corp.). Sample temperature was recorded during each EIS measurement. Samples were allowed to equilibrate with temperature and moist air for $1 \mathrm{hr}$. before testing. No special proton loading treatment was performed prior to sample testing. An in-plane electrical configuration was used for EIS measurements as shown Figure 2.

\section{Results and Discussion}

\subsection{Characterization of $\mathrm{BaCe}_{0.85} \mathrm{Y}_{0.15} \mathrm{O}_{3-\delta}$ Films}

The microstructure and properties of films are strongly dependent on the deposition process. The phase purity and the orientation of the deposited films were examined by XRD. 
Analysis of XRD patterns showed that the orientation is dependent on process conditions. No secondary phase formation was detected from XRD anaylsis for BCY films deposited up to $950{ }^{\circ} \mathrm{C}$. In comparison, $\mathrm{CeO}_{2}$ formation has been observed for magnetron sputtered $\mathrm{BaCe}_{0.9} \mathrm{Y}_{0.1} \mathrm{O}_{3-\delta}$ films as reported by He et al. ${ }^{9}$

Crystal growth along a preferential orientation is observed for all samples as revealed by the enhanced (400) and (002) peaks of the XRD pattern. Preferential growth along the [100] and [001] orientation is observed. Growth of [001] orientated films appears to be less sensitive to process conditions and predominates under most growth conditions as shown in Table I. Growth of the [100] orientation was observed under low laser pulse energy and pressure at $800{ }^{\circ} \mathrm{C}$. The results indicate [100] growth dependence upon laser pulse energy. Temperature, pressure and pulse energy are the main parameters that change film growth. Changing the laser pulse energy changes the kinetic energy of the plume, degree of ionization and amount of ablated material in the vapor. ${ }^{10,11}$ Pressure can reduce the kinetic energy of the plume and molecular clusters in the vapor. Film growth under energetic fluxes is well documented in the literature. ${ }^{4}$ Oriented film growth dependence upon pressure has been reported in the literature for $\mathrm{BaTiO}_{3}$ films fabricated by PLD. ${ }^{12}$ Further work is needed to establish film growth dependency on PLD process conditions.

Figure 1 shows SEM and TEM cross-sections of a BCY film grown over a porous $\mathrm{Al}_{2} \mathrm{O}_{3}$ substrate at $800{ }^{\circ} \mathrm{C}$. The SEM image is a fracture surface exposing the film cross section. Both SEM and TEM reveal a distinct interface between the BCY film and porous $\mathrm{Al}_{2} \mathrm{O}_{3}$ substrate. The crystalline $\mathrm{BCY}$ film has a columnar growth structure which is typical for physical vapor deposited films. No porosity is observed within the fabricated BCY films as shown in figure 1B. Dense films have been fabricated over the temperature range of $700{ }^{\circ} \mathrm{C}$ to $950{ }^{\circ} \mathrm{C}$ at pressures up to 200 mTorr. Figure $1 \mathrm{C}$ and $1 \mathrm{D}$ reveal the nucleation and growth of the $\mathrm{BCY}$ films on the porous substrate. The $\mathrm{Al}_{2} \mathrm{O}_{3}$ particles are nucleation sites for $\mathrm{BCY}$ 
film growth. Film growth does not penetrate into the porous $\mathrm{Al}_{2} \mathrm{O}_{3}$ architecture. Figure 1D reveals that numerous nanocrystals nucleated on the $\mathrm{Al}_{2} \mathrm{O}_{3}$ particle surface. As the film grows, a dominant crystal growth perseveres to form either a [100] or [001] orientated film. As the film continues to grow, a dense BCY film is formed by impingement of growing $\mathrm{BCY}$ columns.

Based on microstructure observations, there is a strong correlation between the width of the columnar grains and the $\mathrm{Al}_{2} \mathrm{O}_{3}$ particle size. This was an unexpected result but it provides another route to engineer the microstructure. Further work is needed to establish the physical size range of this relationship. Our work has shown that a continuous BCY film can not be achieved on porous substrates with an average pore size of $10 \mu \mathrm{m}$.

This work has revealed that there is a significant difference between sintered and thin film microstructures that might affect protonic conduction. A large number of perovskite ceramics are distorted due to geometrical packing of charged particles. For doped $\mathrm{BaCeO}_{3}$, oxygen cage titling occurs because the structure has a low tolerance factor of 0.94 , where $t=\left(R_{A}+R_{O}\right) / \sqrt{ } 2\left(R_{B}+R_{O}\right)^{12}$. The ionic radii of $B a$ is too small to fully occupy the available volume. The oxygen octahedra rotates in order to reduce the size of the cuboctahedral interstices of the oxygen sublattice. The systematic assessment of the tilt phenomenon in $\mathrm{Sr}_{3}\left(\mathrm{~B}^{\prime} \mathrm{B}^{\prime}{ }_{2}\right) \mathrm{O}_{9}$ perovskites, as a function of their tolerance factors has been studied by Colla et al. ${ }^{14}$ Oxygen tilted domains are observed in our work on high temperature processed simple and complex perovskite ceramics. ${ }^{13}$ We have not found any long range ordered oxygen tilted domains in the fabricated BCY films. The BCY films contain a high density of planar defects most likely caused by low angle grain boundaries, interfacial strain and ion flux. Low deposition temperatures might not be adequate for diffusion of atoms to form long range ordered domains or ion bombardment destroys long range ordering. The effect of structural defects on protonic conduction is not well understood. 


\subsection{Electrical Conductivity OF TeXtured BaCe ${ }_{0.85} \mathrm{Y}_{0.15} \mathrm{O}_{3-\delta}$ Films}

The electrical properties of the bulk and thin film samples were measured by EIS. A series of representative spectra over the temperature range of 430 to $568{ }^{\circ} \mathrm{C}$ are shown on a Nyquist plot in Figure 2. Only one arc that is slightly asymmetric is observed in the temperature range of 100 to $950{ }^{\circ} \mathrm{C}$, indicating that bulk and grain boundary responses are indistinguishable. As the temperature is increased, the resistance decreases and the time constants $(R C)$ of the relaxations associated with polarizations are reduced shifting the arcs to higher frequencies.

The impedance data was analyzed by fitting the spectrum using an equivalent electrical circuit of $(\mathrm{RQ})_{\text {Grain }}(\mathrm{RQ})_{\text {GrainBoundary }}(\mathrm{R})_{\text {electrode, }}$, where $R=$ resistance and $\mathrm{Q}=$ constant phase element or CPE. The total conductivities were calculated from the impedance data. Circuit parameters for the equivalent circuits were obtained by using the least squares fitting routine in Zview (Scribner Associates).

The apparent energies for electrical conduction, $\mathrm{Q}$, were determined by plotting $\sigma \cdot \mathrm{T}$ vs 1/RT using the Arrhenius equation of $\sigma \cdot \mathrm{T}=\mathrm{A} \cdot \exp (-\mathrm{Q} / \mathrm{RT})$. Figure 3 is an Arrhenius plot of the electrical conduction data. It should be pointed out that the conduction data is reproducible as shown for two independent samples fabricated at $950{ }^{\circ} \mathrm{C}$. Except for the 900 ${ }^{\circ} \mathrm{C}$ data, the total electrical conductivity of the fabricated films is lower than the sintered sample. Least square analysis was used to obtain the activation energies for electrical conduction. Table II lists the calculated Q values and pre-exponential values for samples measured. The activation energies ranged from $54 \mathrm{~kJ}$ to $115 \mathrm{~kJ}$. Activation energy for protonic conduction reported for HTPC materials ranges from 30 to $120 \mathrm{KJ} / \mathrm{mol}^{15-17}$

The sintered specimen shows an apparent change in electrical conduction behavior above and below $550{ }^{\circ} \mathrm{C}$. A Q value of $100.3 \mathrm{KJ} / \mathrm{mol}$ is calculated for the low temperature electrical conduction and $38.6 \mathrm{KJ} / \mathrm{mol}$ for the high temperature electrical conduction. The most probable cause for conduction change is due to phase transformations. XRD data from 
sintered specimens exhibit second phase formation. It is known that $\mathrm{BaCeO}_{3}$ undergoes phase transformations in the temperature range from 200 to $950{ }^{\circ} \mathrm{C} .{ }^{18}$ Structural studies on $\mathrm{BaCeO}_{3}$ show little evidence that doping introduces major perturbations to the parent structure.

The results show no evidence of electrical conduction dependence upon film thickness. Film thickness dependence has been reported in the literature for oxide films with thicknesses below $1 \mu \mathrm{m} .{ }^{19}$ There is indication from the data that electrical conduction is dependent upon deposition temperature. Electrical conductivity increased with deposition temperature until $900{ }^{\circ} \mathrm{C}$ and decreased at $950{ }^{\circ} \mathrm{C}$. Conversely, the activation energy decreased until $900{ }^{\circ} \mathrm{C}$ and increased at $950{ }^{\circ} \mathrm{C}$. We attribute this dependence upon changes in the film microstructure as the process parameters were changed. Preliminary results on microstructure characterization at $950{ }^{\circ} \mathrm{C}$ indicate significant difference from the microstructure at $800{ }^{\circ} \mathrm{C}$. The film microstructure loses its columnar growth structure and appears to consist of nano-sized grains. Further microstructural characterization will help understand the protonic conduction dependence upon microstructure.

\section{Conclusions}

Temperature dependent protonic conduction was measured in $\mathrm{BCY}$ sintered samples and BCY films. Dense BCY films were fabricated on porous $\mathrm{Al}_{2} \mathrm{O}_{3}$ substrates by PLD. Nanocrystalline films with columnar growth morphology were deposited at $700{ }^{\circ} \mathrm{C}$ to $950{ }^{\circ} \mathrm{C}$ at pressures up to 200 mTorr of $\mathrm{O}_{2}$. Preferential orientated growth is observed along the [100] and [001]. The [001] growth predominates most PLD process conditions, the [100] growth shows dependency upon laser pulse energy. Electrical conduction of BCY films show dependency upon deposition temperature. Maximum electrical conduction occurred at $900{ }^{\circ} \mathrm{C}$, it exceeds the sintered specimen. All other BCY films exhibit a lower electrical conduction than the sintered specimens. Total electrical conductivity followed Arrhenius behavior. 
Activation energy for electrical conduction showed dependence upon deposition temperature. The activation energy varied from $54.1 \mathrm{KJ}$ to $115.5 \mathrm{KJ}$. Film microstructure was attributed to difference in difference in BCY electrical conductivity.

\section{Acknowledgments}

Financial support for this work was obtained from following sources: (1) NASA Glenn Research Center, Brookpark, Ohio under cooperative agreement NCC3-850 through NASA's Internal Research and Development Program and (2) European Office of Aerospace Research and Development funded by AFOSR under grant no. FA8655-03-1-3040.

\section{References}

[1] H. Iwahar et al., Solid State Ionics, 11, 1983, 109.

[2] S. Hamakawa et al., Solid State Ionics 48, 2002, 71.

[3] K.D. Kreuer et al., Solid State Ionics 145, 2001, 295.

[4] D. E. Chrisey (Ed.), Pulsed Laser Deposition of Thin Films, Wiley \& Sons, N.Y., 1994.

[5] I. Kosacki et al., Electrochem Soc., Proc., 97, 1998, 631.

[6] T. Suzuki et al., J. Am. Ceram. Soc., 84, 2001, 2007.

[7] H.L. Tuller, Solid State Ionics 131, 2000, 143.

[8] F. Dynys et al., Cer. Eng. \& Sci. Proc., 25, 2004, 293.

[9] T. He et al., Solid State Ionics 89, 1996, 9.

[10] Y. Tasaka et al., Thin Solid Films, 281-282, 1996, 441.

[11] E. W. Kreutz \& J. Gottmann, Phys. Stat. Sol. (A) 166, 1998, 569.

[12] D. Y. Kim et al., Materials Letters 40_1999.146-150

[13] M.-H. Berger \& A. Sayir, Cer. Eng. \& Sci. Proc., 25, 2004, 351.

[14] E. L. Colla et al., J. Appl. Phys., 74, 1993, 3414.

[15] R.C.T. Slade et al., Solid State Ionics 82, 1995, 135. 
[16] R.C.T. Slade \& N. Singh, Solid State Ionics 46, 1991, 111.

[17] M. Laidoudi et al, J. Phys. D: Appl. Phys. 33, 2000, 3112.

[18] K.S. Knight, Solid State Ionics, 74, 1994, 109.

[19] I. Kosacki et al., Solid State Ionics, 176, 2005, 1319. 

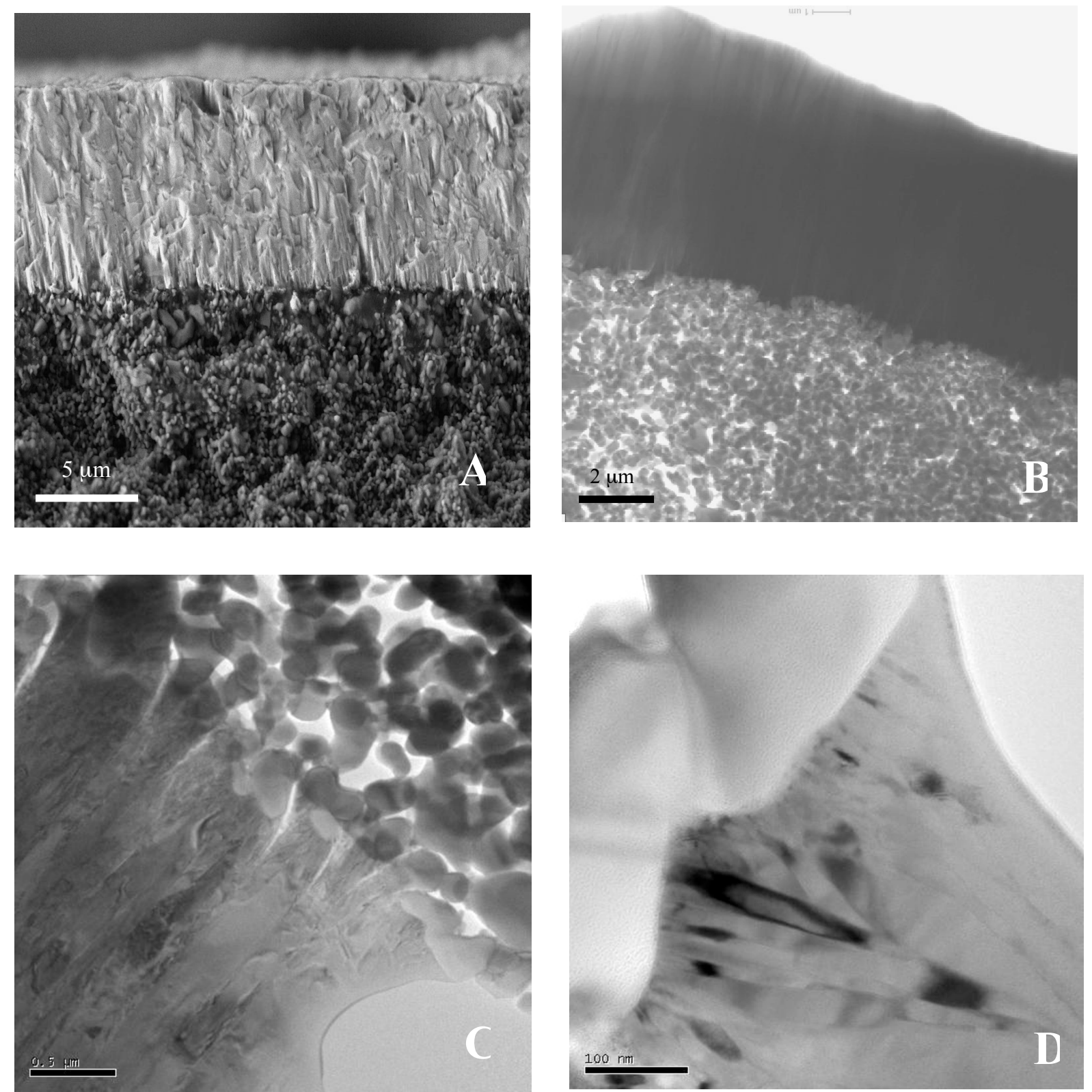

Figure 1. SEM and TEM micrographs of a BCY film fabricated at $800{ }^{\circ} \mathrm{C}$. 


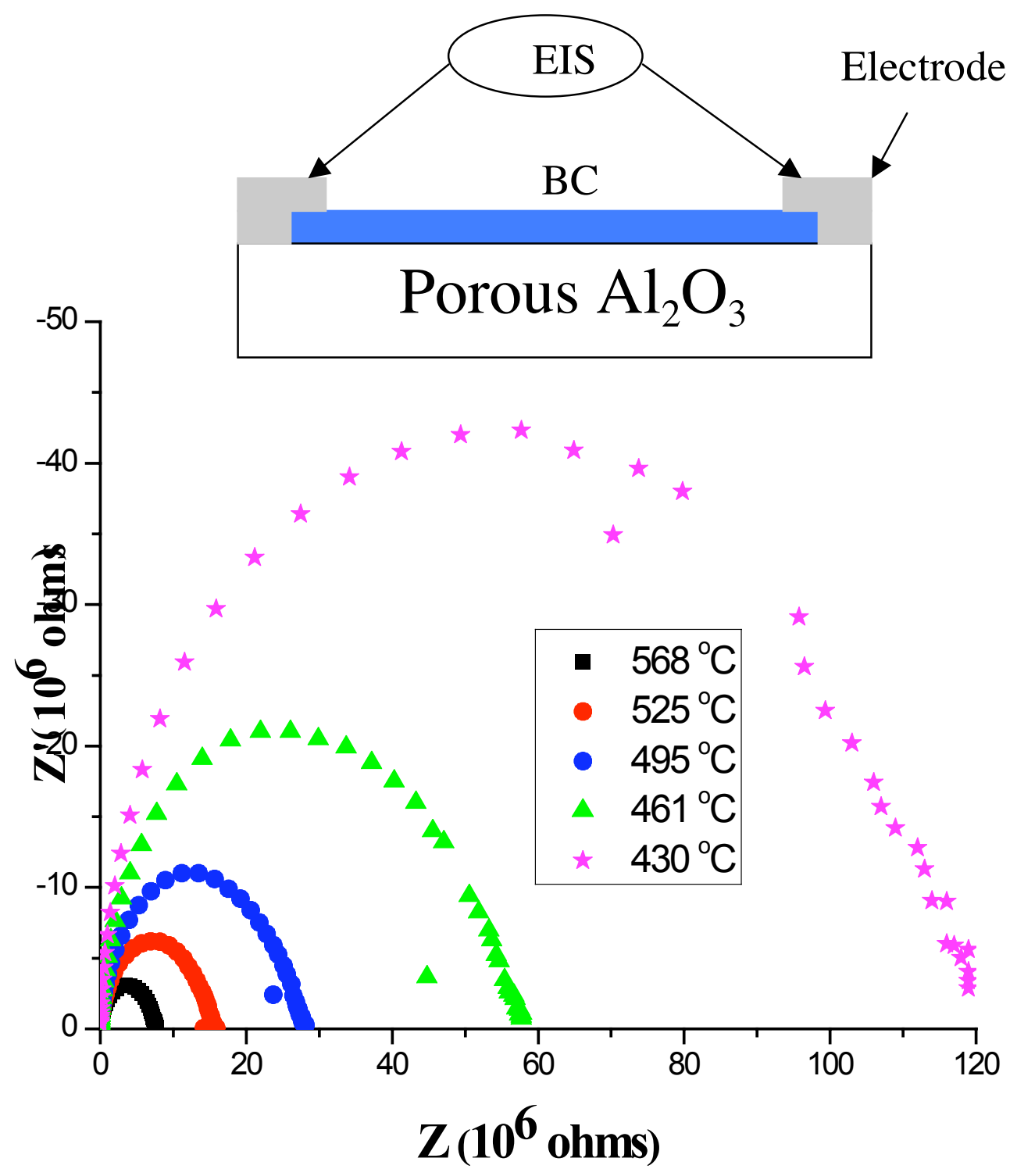

Figure 2. Impedance spectrums at different temperatures for BCY film fabricated at $800{ }^{\circ} \mathrm{C}$. 


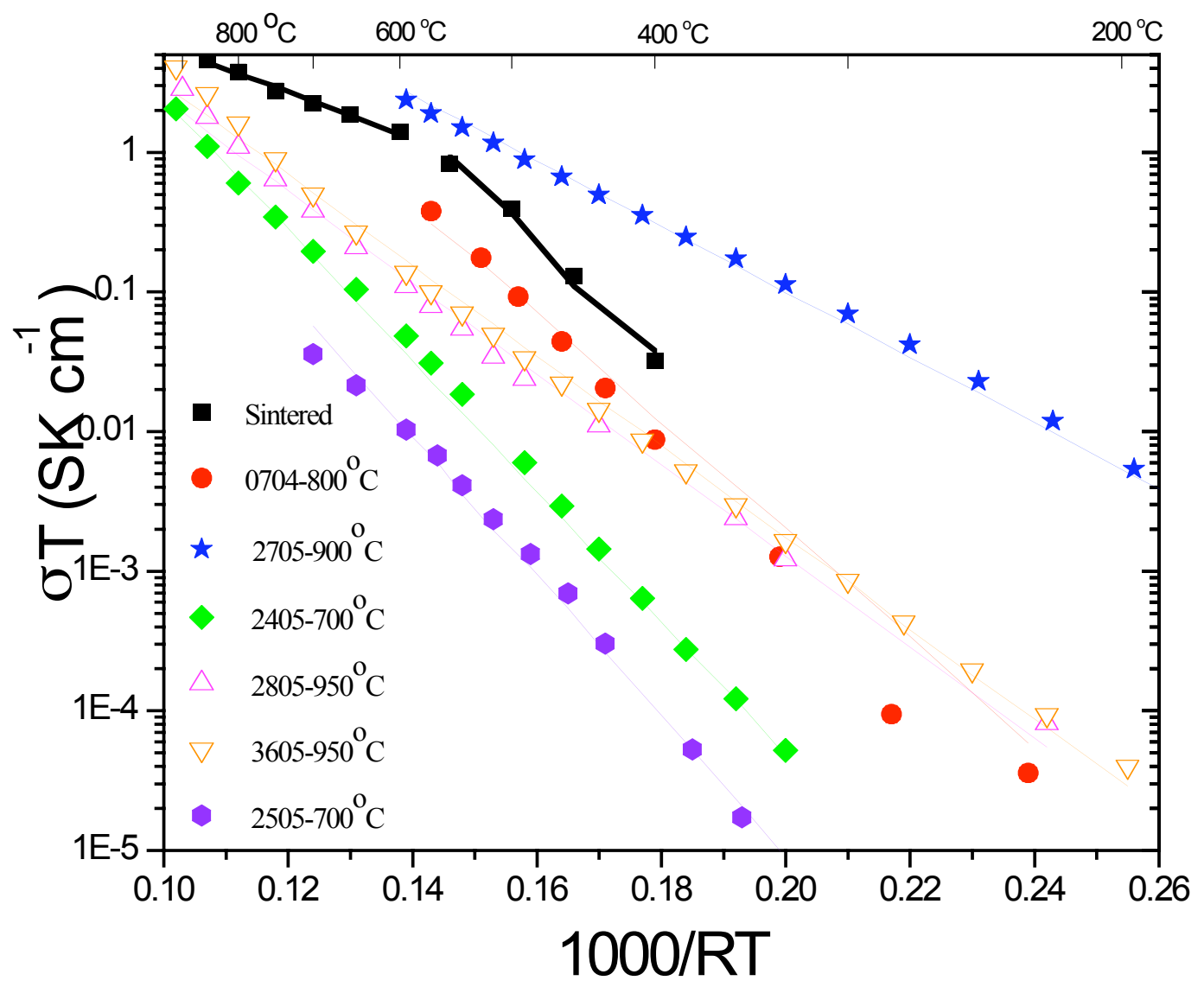

Table II

Activation Energy

\begin{tabular}{|c|c||c||c||}
\hline \hline & $\begin{array}{c}\text { Temp. } \\
\left({ }^{\mathbf{0}} \mathbf{C}\right)\end{array}$ & $\begin{array}{c}\text { Activation } \\
\text { Energy } \\
\text { (KJ/mol) }\end{array}$ & $\begin{array}{c}\text { Pre-exponential } \\
\text { (SK/cm) }\end{array}$ \\
\hline \hline $\mathrm{BaCe}_{0.85} \mathrm{Y}_{0.15} \mathrm{O}_{3-\delta}$ & $600-850$ & 38.6 & 275.6 \\
$\mathrm{Bulk}^{\circ}$ & $400-550$ & 100.3 & $2.15 \times 10^{6}$ \\
\hline \hline $3605-950{ }^{\circ} \mathrm{C}$ & $200-900$ & 74.8 & 5535 \\
\hline \hline $2805-950{ }^{\circ} \mathrm{C}$ & $250-900$ & 75.4 & 4447 \\
\hline \hline $2705-900{ }^{\circ} \mathrm{C}$ & $200-600$ & 54.1 & 5004 \\
\hline \hline $0704-800{ }^{\circ} \mathrm{C}$ & $100-500$ & 89.1 & $1.06 \times 10^{5}$ \\
\hline \hline $2505-700{ }^{\circ} \mathrm{C}$ & $400-700$ & 115.5 & 98125 \\
\hline \hline $250-700{ }^{\circ} \mathrm{C}$ & $375-900$ & 108.3 & 122149 \\
\hline
\end{tabular}

Figure 3. Arrhenius plot and measured activation energies for electrical conduction for sintered BCY sample and BCY films. 